\title{
Hard-type anharmonicity gap discrete breather in 2D biatomic crystal
}

\author{
A. S. Semenov ${ }^{1}$, S. Yu. Fomin ${ }^{2, \dagger}$, K. Zhou ${ }^{3}$, E. G. Soboleva ${ }^{4}$ \\ †fomin.s.yu@yandex.ru \\ ${ }^{1}$ Mirny Polytechnic Institute (branch) of North-Eastern Federal University, 5/1 Tikhonov st., 678175, Mirny, Russia \\ ${ }^{2}$ Ufa State Aviation Technical University, 12 K. Marx St., 450000, Ufa, Russia \\ ${ }^{3}$ Nanyang Technological University, 50 Nanyang Ave, 639798, Singapore \\ ${ }^{4}$ Yurga Institute of Technology (branch) of National Research Tomsk Polytechnic University, 26 Leningradskaya st., 652050, \\ Yurga, Russia \\ Spatially localized nonlinear oscillations in the form of a discrete breather (DB) is a recently discovered phenomenon widely \\ investigated in different physical systems due to its potential impact on the structure and dynamics of those systems. Our \\ molecular dynamics research is focused on the variety of DB in crystals. Depending on the type of the crystal and corresponding \\ phonon spectrum one can get a gap DB or a DB with the frequency above the phonon spectrum. Most of gap DBs previously \\ addressed in the literature were characterized by a soft nonlinearity type with frequencies splitting off from the upper edge of \\ the phonon spectrum gap. In this work we managed to excite a hard nonlinearity type DB with a frequency within the band \\ gap. In order to achieve this goal we have excited four types of delocalized vibrational modes in biatomic crystal with atomic \\ mass difference $m_{1} / m_{2}=10$ providing the existence of sufficiently wide phonon band gap. Analysis of amplitude-frequency \\ dependences of two of those modes obtained in molecular dynamics simulations revealed the hard nonlinearity type with the \\ frequency within the spectrum. The fourth mode with moving heavy atoms had the frequency within the band gap growing \\ with the amplitude. Application of localization function with radial symmetry to this delocalized vibrational mode allowed us \\ to obtain a DB with hard nonlinearity type in the band gap within the considered model of the crystal. Properties of the DB \\ were analyzed.
}

Keywords: nonlinear dynamics, 2D lattice, phonon band, discrete breather.

\section{Дискретный бризер с жестким типом нелинейности в двумерном биатомном кристалле}

\author{
Семенов А.С. ${ }^{1}$, Фомин С. Ю. ${ }^{2, \dagger}$, Жоу К. ${ }^{3}$, Соболева Э. Г. ${ }^{4}$ \\ †fomin.s.yu@yandex.ru \\ ${ }^{1}$ Политехнический институт (филиал) ФГАОУ ВО "Северо-Восточный федеральный университет имени \\ М.К.Аммосова" в г. Мирном, ул. Тихонова 5/1, 678175, Мирный, Россия \\ ${ }^{2}$ Уфимский государственный авиационный технический университет, ул. К. Маркса, 12, 450000, Уфа, Россия \\ ${ }^{3}$ Наньянский технологический университет, авеню Наньян 50, 639798, Сингапур \\ ${ }^{4}$ Юргинский технологический институт (филиал) ФГАОУ ВО «Национальный исследовательский Томский \\ политехнический университет», ул. Ленинградская 26, 652055, Юрга, Россия
}

Пространственно локализованные нелинейные колебания в форме дискретных бризеров были открыты около трех десятилетий назад и в настоящее время являются объектом для интенсивного изучения в различных физических системах ввиду возможности их значительного влияния на структуру и динамику этих систем. Наша работа посвящена молекулярно-динамическому исследованию возможного многообразия конфигураций и типов дискретных бризеров в кристаллах. В зависимости от типа кристалла и его фононного спектра могут быть реализованы дискретные бризеры с частотой выше фононного спектра либо в его щели. Большинство описанных в литературе бризеров с частотой в щели фононного спектра характеризовались мягким типом нелинейности амплитудно-частотная зависимость которых отщеплялась от верхней границы щели. В данной работе нам удалось возбудить бризер с жестким типом нелинейности частота которого отщепляется от нижней границы спектра и сконцентрирована на тяжелых 
атомах биатомной решетки. Для этого в двумерном модельном кристалле стехиометрии АЗВ с разницей масс тяжелых и легких атомов $m_{1} / m_{2}=10$ были возбуждены несколько коротковолновых фононных мод с волновым вектором на границе первой зоны Бриллюэна. Анализ полученной посредством моделирования амплитудно-частотной зависимости мод локализованных на легких атомах решетки выявил жесткий тип нелинейности и частоту в пределах фононного спектра. Для случая локализации моды на тяжелых атомах ячейки частота моды находилась в щели фононного спектра. Наложение на данную моду радиально симметричной функции локализации позволило в рамках рассматриваемой модели получить дискретных бризер с жестким типом нелинейности и частотой в щели фононного спектра, а также проанализировать его свойства.

Ключевые слова: нелинейная динамика, двумерные решетки, фононный спектр, дискретный бризер.

\section{Introduction}

It is well known that most of condensed matter objects possess crystalline long range order structure with inevitable presence of defects. Those defects are divided into several types depending on their dimensionality and formation energy. Each of those has own contribution to structure dynamics and properties. External impacts, for example, strain, heat, radiation result in the evolution of defect structure associated with their generation, annihilation and migration processes. All of the latter are associated with overcoming the potential barriers which is, in turn, related to energy localization phenomena. It is of particular importance for lattices subjected to external impact connected with introduction of energy into the crystal. One of the possible ways of energy localization in small area of the crystal is the excitation of discrete breathers (DB) - nonlinear, spatially localized vibrational modes in defect free lattices that are reported to exist in many areas of modern physics [1-3]. Introducing the concept of DB, being in fact a dynamical defect in perfect lattice, to the energy localization process can allow to shed light on many physical effects and to attempt to control energy localization in crystals. Existence of DB is provided by anharmonicity of the interatomic forces, leading to a dependence of atoms oscillation frequency upon amplitude. DB do not resonate with phonons due to the fact that their oscillation frequency lies out of the phonon spectrum of crystals. For this reason, in idealized cases, they do not excite phonons and not lose energy over time [ $1-3]$. In crystals with realistic interatomic potentials investigated by means of molecular dynamics one can expect only DBs with finite lifetime. However in thermal equilibrium their concentration can grow following the Arrhenius law thus increasing their possible impact on defect structure evolution.

DB can be characterized by two types of nonlinearity. In case of soft nonlinearity type frequency decreases with increasing amplitude, hard nonlinearity type is characterized by frequency growth with increasing DB amplitude [3]. Generally DBs with soft nonlinearity type exist in biatomic crystals with notable atomic mass difference and have the frequency within the phonon band gap. This type of breather is usually localized on one light atom and is very easy to excite simply by introducing initial velocity or initial displacement to the atom. For this reason such type of DBs were widely investigated in many biatomic systems and are well addressed in the literature [4-7].

DBs with hard nonlinearity type and having frequency above the spectrum are expected to exist in monoatomic crystals with gapless band. Until recently it was believed that in real crystals interatomic interactions tend to exhibit a soft type of nonlinearity, and DB can only exist within a gap in the phonon spectrum of the crystal [8]. However, in [9] a possibility of existence of DB with hard type of nonlinearity and with frequencies above the phonon spectrum was demonstrated by means of molecular dynamics modeling for $\mathrm{Ni}$ and $\mathrm{Nb}$. Later the possibility of the existence of DB with frequencies above the phonon spectrum of the crystal was confirmed in [10-11] for the case of two-dimensional (2D) monoatomic crystal with Morse interatomic potential.

Another important aspect of DB investigation is the method of their excitation which consists in introduction of initial velocities and displacement to atoms involved in the DB oscillations. The most common ways of excitations were direct introduction of displacements to several atoms as it was commonly done for ionic crystals [4], metals [9], and $\mathrm{sp}^{2}$ carbon materials [12-15]. Another progressive method of DB excitation in a closely packed atomic raw was application of the ansatz - a set of initial functions determining initial vibration amplitudes, atomic vibration centers shifts and other DB parameters. This way is more common and was successfully employed for Morse crystals of different dimensionality [10-11] and for several metals [16-17].One should also recall that p'ossibility of DB excitation and their properties strongly depend on the type of interatomic potential considered in molecular dynamics simulation.

Next step in the development of DB excitation methods was the investigation of delocalized nonlinear modes [18]. Application of localization function to those modes turned out to be a universal way to excitation of DBs of different types of symmetry in various crystals including graphene [15], Morse crystals [19-20] and metals [21].

In this work we have tried to extend the approach of localization of nonlinear modes to the biatomic Morse crystal with a wide band gap in order to make an attempt to obtain a new type of the DB with hard nonlinearity type and the frequency within the phonon band gap.

\section{Simulation details}

We consider a model of biatomic 2D close-packed crystal of $\mathrm{A}_{3} \mathrm{~B}$ stoichiometric with the interatomic distance $a$. Without loss of generality, the mass of light atoms $m_{1}$ is considered to be unity. Mass of heavy atoms $m_{2}=10 m_{1}$. Model of the crystal lattice is shown in Fig. 1a (color online) where green color corresponds to heavy atoms and yellow to light atoms. The interaction between atoms is described by the pairwise 
Morse potential:

$$
V(r)=D\left(e^{-2 \alpha\left(r-r_{m}\right)}-2 e^{-\alpha\left(r-r_{m}\right)}\right),
$$

where $r-$ is the distance between a pair of atoms and $D, \alpha$, $r_{m}$ - potential parameters. The function $U(r)$ has a minimum at $r=r_{m}$, minimum depth (bond rupture energy) is $D$, and the parameter $\alpha$ determines the bond stiffness. Without loss of generality one can put $r_{m}=1$ and $D=1$, selecting the appropriate unit of distance and energy. For the parameter $\alpha$ determining the rigidity of the interatomic bond the value $\alpha=5$ was considered. For the selected cut-off radius of $7.5 \AA$, the equilibrium lattice parameter makes $0.988 \AA$. The size of the cell used in the calculation was equal to $192 \times 192$ atoms with the imposed periodic boundary conditions. Equations of atomic motion for the atoms in the periphery of the calculation cell had an imposed viscosity term in order to avoid the impact of low-amplitude waves emitted by the discrete breathers caused by the inaccuracy of the initial conditions.

Three types of delocalized vibrational modes schematically shown on Fig. 1b-1d were realized in the crystal. Amplitude-frequency analysis of all modes revealed that all modes located on light atoms demonstrated a hard nonlinearity type with the frequency within the upper part of the phonon spectrum. The mode shown in Fig. 1d is located on heavy atoms and has a frequency growing with amplitude within the band gap (Fig. 2). One can see that the frequency of the mode splits from the lower limit of the phonon band and lies within the spectrum gap. This fact allows an attempt of excitation of a DB based on the latter mode. One should mention that realization of those modes in the crystal can result in elastic properties modification [22] and modulation instability being a reason for excitation of random DBs [23].

In order to excite the DB the exponentially localized bell-shaped function was on the planar phonon mode. The center of the bell-shaped function was placed at the point equidistant from three neighboring oscillating atoms. If the coordinates of this point are assumed to be $\left(x_{0}, y_{0}\right)$ the amplitude of the oscillations of the atom with the coordinates $(x, y)$ at the distance $R=\sqrt{\left(x-x_{0}\right)^{2}+\left(y-y_{0}\right)^{2}}$ from the center of the discrete breathers can be expressed as [19]

$$
A(R)=\frac{T}{\cosh (\beta R)},
$$

where $T-$ is the amplitude of the bell shape function and $\beta$ defines its degree of localization.

Shift of vibration centers can be defined by the expression

$$
S(R)=\frac{s R}{\cosh (\gamma R)}
$$

describing the exponential localization and displacements of vibrational centers of atoms in the core of the DB.

Due to the asymmetry of the Morse potential shape one also take into account that the centers of oscillations of atoms are displaced radially from the point $\left(x_{0}, y_{0}\right)$. It was shown analytically in [19] using linear elasticity theory that the static field of the radial displacements of atoms caused by the discrete breathers in the two-dimensional crystal at large distances decreases as $1 / R$, i.e., rather slowly.

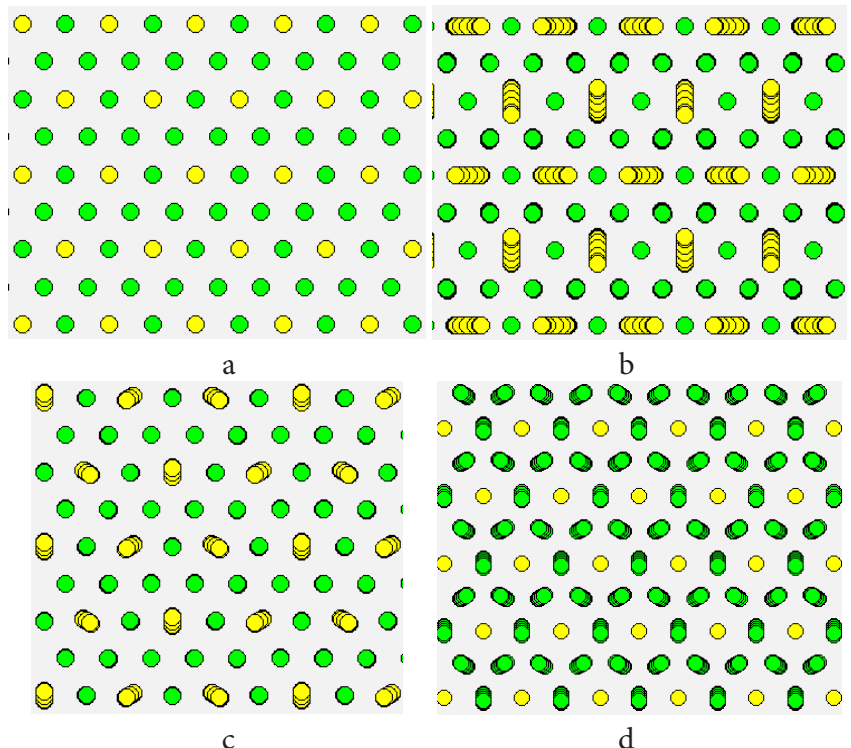

Fig. 1. (color online) (a) Two-dimensional biatomic crystal of $A_{3} B$ stoichiometry based on the triangular lattice. Stroboscopic pattern of atomic motion of delocalized vibrational modes in the biatomic lattice with moving light $(\mathrm{b}, \mathrm{c})$ and heavy $(\mathrm{d})$ atoms.

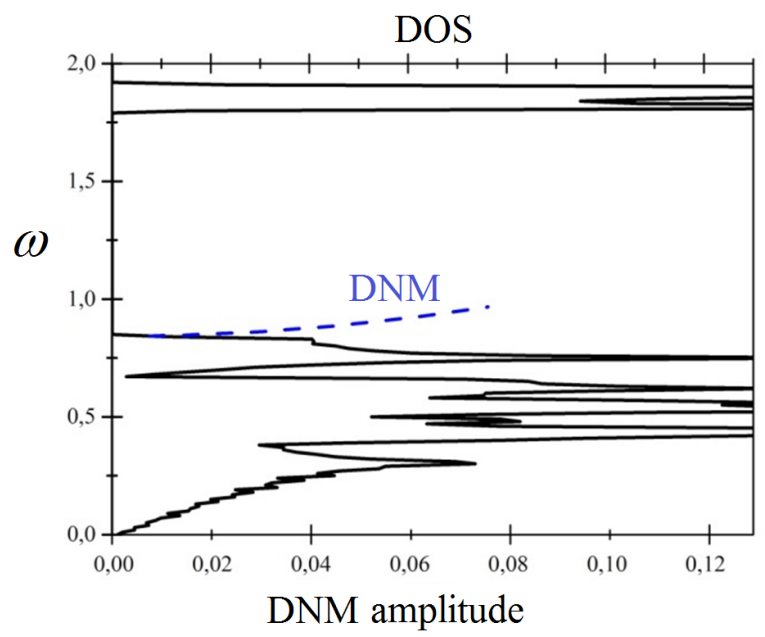

Fig. 2. (color online) Density of phonon states (black solid line) and frequency as the function of amplitude for the delocalized vibrational mode shown in Fig. 1d (blue dashed line).

\section{Numerical results}

Stroboscopic picture of atomic motion for the DB excited on heavy atoms with the help of bell-shaped localizing function applied to the delocalized vibrational mode is shown in Fig. 3. The breather has radial symmetry and has a radius about ten interatomic distances in every direction. Structure of the DB is similar to one in monoatomic 2D crystal described in [19]. The part of the crystal around the DB core partially suppresses the thermal expansion of the atoms and this fact increase the contribution of hard core of Morse potential in the nonlinear dynamic of the lattice allowing the $\mathrm{DB}$ existence.

Properties of the DB, namely dependences of vibration amplitudes, $A$, and displacements of vibration centers, $S$, as the functions of distance from the DB center, $R$ are shown in Fig. 4. Dots show the numerical result after 10 periods 
of DB oscillation. A set of green dots close to the zero level corresponds to almost immobile light atoms. Scattering of values of initial functions and numerical results increases upon the growth of the DB amplitude.

An important feature of this $\mathrm{DB}$ is the vibration localization on heavy atoms of the lattice. Previous studies of DB in biatomic lattices were concentrated on light atom based breathers with soft nonlinearity type. Excitation of the phonon mode that involves all heavy atoms in the lattice provides a high nonlinearity type behavior. This allows the existence of the gap DB with hard nonlinearity. So one can conclude that application of new methods of DB excitation results in new types of DBs that were not earlier reported in literature.

Dependence of the energy $E$, frequency $\omega$ and localization parameter $\delta$ on the amplitude of the $\mathrm{DB}$ are shown in Fig. 5. All three functions demonstrate the monotonously increasing behavior. Lifetime of the $\mathrm{DB}$ makes about one hundred period of vibrations and one should notice that the investigated object is in fact a quasibreather. The concept of quasibreather was proposed in [24]. This object related to crystal lattices is a numerical result of molecular dynamics and has a limited lifetime.

\section{Conclusions}

A new approach for DB excitation in molecular dynamics simulations has been successfully applied to a two dimensional biatomic lattice of $\mathrm{A} 3 \mathrm{~B}$ stoichiometry. The phonon mode excited in the crystal is localized on heavy atoms of the lattice. Light atoms are almost immobile and do not contribute to the lattice dynamics. For this reason the resulting DB is similar to the breather in monoatomic crystal reported in [19]. This type of DB involves a considerable amount of atoms and concentrates relatively large energy. This can decrease the potential barrier of defect formation and migration. In case of biatomic crystal one can expect a stronger barrier overcoming effect on light atoms.

Another important conclusion is the relevance of the investigation of new methods of DB excitations. The efficiency of the approach used in this work was already approved for $3 \mathrm{D}$ crystals with realistic interatomic potentials and new types of DB were obtained. These new configurations of DB could hardly be realized with any other method used previously for setting initial conditions.

This leads us to the conclusion that one should never underestimate the importance of searching for new routes of DB excitation.

Aknowledgements. This work was financially supported by the Russian Science Foundation, project no. 16-12-10175.

\section{References}

1. S. Dolgov, Sov. Phys. Solid State 28, 907 (1986).

2. A. J. Sievers, S. Takeno. Phys. Rev. Lett. 61, 970 (1988).

3. S. V. Dmitriev, E.A. Korznikova, Y.A. Baimova, M. G. Velarde, Physics-Uspekhi 59 (5), 446 (2016).

4. L.Z. Khadeeva, S. V. Dmitriev. Phys. Rev. B. 2011. V 84, 144304.

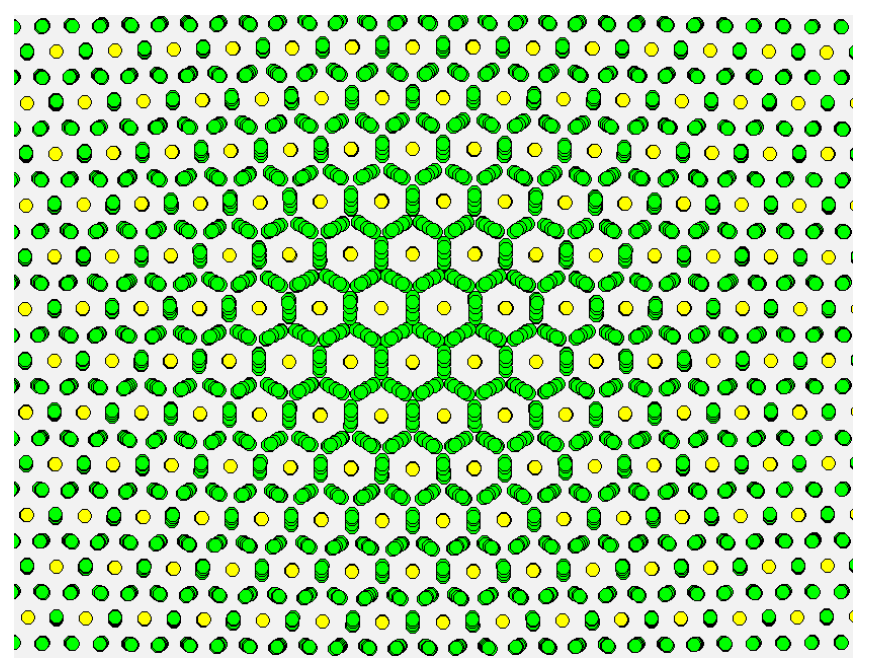

Fig. 3. (color online) Stroboscopic pattern of the motion of atoms near the discrete breathers obtained by imposing the bell-shaped localization function on the short wavelength phonon mode in the nonlinear regime. The displacements of atoms are magnified by a factor of 7 for visibility. The DB was excited with the following parameters: $A=0.06 ; \beta=0.18 ; \delta=0.011 ; \gamma=0.162$. DB energy is equal to 62.56 . DB frequency is 0.844 .

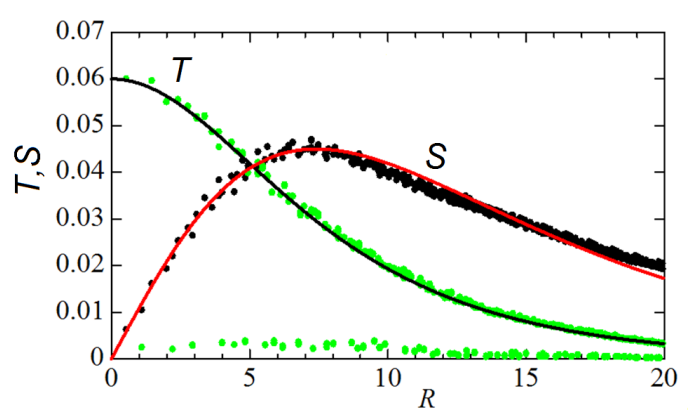

Fig. 4. (color online) Dependences of vibration amplitudes, $T$, and displacements of vibration centers, $S$, as the functions of distance from the DB center, $R$. Solid lines show the dependences initially set by expressions (2), (3). Dots show the numerical result after 10 periods of $\mathrm{DB}$ oscillation. The $\mathrm{DB}$ was excited with the following parameters: $A=0.06 ; \beta=0.18 ; \delta=0.011 ; \gamma=0.162$. DB energy is equal to 62.56 . DB frequency is 0.844 .

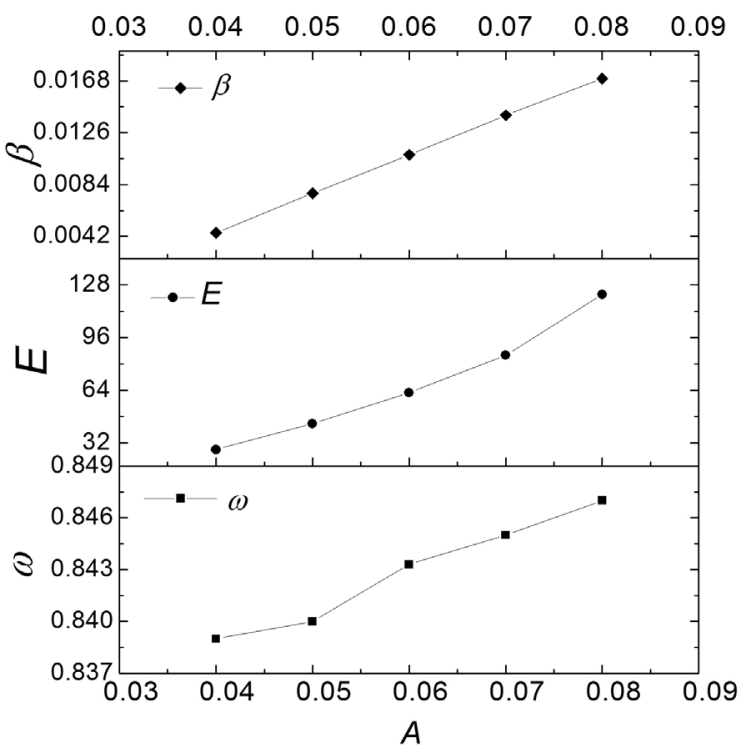

Fig. 5. Dependence of the DB localization parameter, $\beta$, energy, $E$, frequency, $\omega$, on the amplitude of the DB. 
5. P.V. Zakharov, M.D. Starostenkov, A.M. Eremin, E. A. Korznikova, S. V. Dmitriev, Phys. Solid State, 59 (2), 223 (2017).

6. J.A. Baimova, E.A. Korznikova, I.P. Lobzenko, S. V. Dmitriev, Rev. Adv. Mater. Sci. 42, 68 (2015).

7. G. M. Chechin, S. V. Dmitriev, I. P. Lobzenko, D. S. Ryabov, Phys. Rev. B 90, 045432 (2014).

8. S. A. Kiselev and A. J. Sievers, Phys. Rev. B 55, 5755 (1997).

9. M. Haas, V. Hizhnyakov, A. Shelkan, M. Klopov, A. J. Sievers. Phys. Rev. B84, 144303 (2011).

10. E. A. Korznikova, S. Y. Fomin, S. V. Dmitriev, Materials Science Forum, 845, 211 (2016)

11. E.A. Korznikova, A.A. Kistanov, K.S. Sergeev, D. A. Shepelev, A. R. Davletshin,, D. I. Bokii, S. V. Dmitriev, Letters on Materials 6 (3), 221 (2016).

12. E.A. Korznikova, J.A. Baimova, and S.V. Dmitriev, Europhys. Lett. 102(6), 60004 (2013).

13. E.A. Korznikova, A.V. Savin, Yu.A. Baimova, S. V. Dmitriev, and R.R. Mulyukov, JETP Lett. 96 (4), $222-226$ (2012)

14. I.P. Lobzenko, G.M. Chechin, G.S. Bezuglova, Yu. A. Baimova, E. A. Korznikova, S. V. Dmitriev, Phys. Solid State 58 (3), 616-622 (2016).

15. E. Barani, I. P. Lobzenko, E. A. Korznikova, E. G. Soboleva,
S. V. Dmitriev, K. Zhou, A. Moradi Marjaneh, Eur. Phys. J. B 90, 38 (2017).

16. R. T. Murzaev, R. I. Babicheva, K. Zhou, E. A. Korznikova, S. Yu. Fomin, V.I. Dubinko, and S.V. Dmitriev, Eur. Phys. J. B 89 (7), 168 (2016).

17. A.A. Kistanov, S.V. Dmitriev, A.S. Semenov, V.I. Dubinko, D. A. Terent'ev. Technical Physics Letters. 40(8), 657 (2014).

18. G. Chechin, D. Ryabov, S. Shcherbinin, Letters on Materials 6, 9 (2016).

19. E. A. Korznikova, S.Y. Fomin, E. G. Soboleva, S. V. Dmitriev, JETP Letters, 103 (4), 277 (2016).

20. E. A. Korznikova, S. Y. Fomin, Letters on Materials, 6 (1), $57(2016)$

21. I.P. Lobzenko, P.V. Lobzenko, A.M. Bayazitov, A.P. Chetverikov, R.I. Machmutova, A.A. Kistanov, Letters on materials, 6 (4), 304-308 (2016).

22. S. V. Dmitriev, E.A. Korznikova, D. I. Bokij, K. Zhou, Phys. Status Solidi B, 253 (7), 1310 - 1317 (2016).

23. E. A. Korznikova, D.V. Bachurin, S.Y. Fomin, A. P. Chetverikov, S. V. Dmitriev, Eur. Phys. J. B 90 (2), 23 (2017).

24. G. M. Chechin, G. S. Dzhelauhova, and E. A. Mehonoshina, Phys. Rev. E 74, 036608 (2006). 